NBER WORKING PAPER SERIES

\title{
WHO WINS AND WHO LOSES? PUBLIC TRANSFER ACCOUNTS FOR US GENERATIONS BORN 1850 TO 2090
}

\author{
Antoine Bommier \\ Ronald Lee \\ Timothy Miller \\ Stephane Zuber \\ Working Paper 10969 \\ http://www.nber.org/papers/w10969 \\ NATIONAL BUREAU OF ECONOMIC RESEARCH \\ 1050 Massachusetts Avenue \\ Cambridge, MA 02138 \\ December 2004
}

Research for this paper was funded by a grant from NIA, R37-AG11761. Wenlan Qian carried out preliminary empirical estimates. David Cutler generously provided us with the data used for his generational accounts of Medicare. We have received helpful comments from Kent Smetters, Michael Hurd, and participants in both the Berkeley Public Finance Seminar and the 2004 NBER Summer Institute on Economics of Aging. The views expressed herein are those of the author(s) and do not necessarily reflect the views of the National Bureau of Economic Research.

(C) 2004 by Antoine Bommier, Ronald Lee, Timothy Miller, and Stephane Zuber. All rights reserved. Short sections of text, not to exceed two paragraphs, may be quoted without explicit permission provided that full credit, including (C) notice, is given to the source. 
Who Wins and Who Loses? Public Transfer Accounts for US Generations Born 1850 to 2090 Antoine Bommier, Ronald Lee, Timothy Miller, and Stephane Zuber

NBER Working Paper No. 10969

December 2004

JEL No. H0

\begin{abstract}
Public transfer programs in industrial nations have massive long term fiscal imbalances, and apparently permit the elderly to benefit through pension and health care programs at the cost of the young and future generations. However, the intergenerational picture is turned upside down when public education is included in generational accounts along with pensions and health care. We calculate the net present value (NPV) of benefits received minus taxes paid for US generations born 1850 to 2090, and find that all generations born from 1950 to 2050 are net gainers, while many of today's old people are net losers. Windfall gains for early generations when Social Security and Medicare started up partially offset windfall losses when public education was started, roughtly consistent with the Becker-Murphy theory.
\end{abstract}

$\begin{array}{ll}\begin{array}{l}\text { Antoine Bommier } \\ \text { University of Toulouse } \\ \text { antoine.bommier@univ-tlse1.fr }\end{array} & \begin{array}{l}\text { Timothy Miller } \\ \text { Department of Demography } \\ \text { University of California, Berkeley } \\ \text { 2232 Piedmont Avenue } \\ \text { Berkeley, CA 94720 } \\ \text { tmiller@demog.berkeley.edu }\end{array} \\ \begin{array}{l}\text { Department of Demography } \\ \text { University of California, Berkeley } \\ \text { 2232 Piedmont Avenue }\end{array} & \begin{array}{l}\text { Stephane Zuber } \\ \text { Ecole normale superieure, Paris } \\ \text { and NBER }\end{array} \\ \text { rlee@demog.berkeley.edu } & \text { stephane.zuber@ens.fr }\end{array}$




\section{Introduction}

Virtually all industrial nations have instituted public sector program to provide public education, health care (at least for the elderly), and pay as you go pensions on a nearly universal basis. Many Third World nations are following their example. The fiscal pressures to which public pensions and health care will give rise as populations age in the $21^{\text {st }}$ century are well known. For the most part, nations have left programs in place that are seriously fiscally unbalanced and demonstrably unsustainable, but the clamor for reform grows louder each year, while the public strongly resists any reduction in benefits.

If the necessity to reform social security and health care is undisputed, there is strong disagreement about how that reform should be designed. Some argue for a rapid reform, so that future generations are not unfairly saddled with the burden of a large public debt. Others suggest that rapid reform would be unfair to current generations, especially those near retirement.

The notion of fairness is therefore central to the discussion. If the notion of fairness is generally difficult to define in, the intergenerational dimension makes it even more so. Various approaches have been suggested: utilitarianist, Rawlsian, accounting, etc. These approaches can substantially differ, but they have in common that they adopt a longitudinal view. Actually, for most people, it would make little sense to discuss the fairness of pension benefits without considering contributions.

Surprisingly, discussions of one kind of transfer are persistently framed horizontally rather than longitudinally: education. Public education is generally seen as an investment in human capital, but rarely as an intergenerational transfer. Economists argue about the optimal amount to be spent on education, but pay little attention to the questions of intergenerational equity that would naturally accompany the development of educational transfers. For some reason, while we tend to think of the pension and health benefits we receive in old age as a kind of return earned on an earlier investment of contributions, when it comes to education, we think of it cross-sectionally, not as a benefit we receive early in life and then pay for later through our school taxes.

Nonetheless, there are many reasons to include educational transfers in the debate on intergenerational equity, and to consider public education transfers on the same basis as social security and health care. First, education is an extremely important public transfer. In the US in 2000, Education was the largest public transfer program at $4.5 \%$ of GNP, followed by OASI (pensions and survivor's benefits) at 3.7\% and Medicare at $2.1 \%$. Second, due to their timing in the life-cycle, education transfers appear even more important when we take discounting into account. The benefits of public education are received on average about thirty years earlier than the average age of paying taxes, which is in turn about thirty years earlier than the average age of receiving old age benefits. Each 30 years of discounting at 3\% introduces a discount factor of .4, so a dollar of education received as a child carries a relatively great weight in the longitudinal accounts. It is 2.5 times greater than the taxes paid for education later in life, and six times greater than a dollar of benefits received in old age. Taking survival probabilities into account, a dollar of educational benefits can easily be worth ten dollars of old age benefits. Third, in 
contrast to Social Security and Medicare, Education is a downward transfer: a transfer that flows from older to the younger members of the population. Consequently, it may offset some of the effects of upward transfers and give rise to interesting results. The most striking example is that of Becker and Murphy (1988) who explain that when considered separately, the introduction of social security and education transfers were not Pareto improving reforms, when considered in combination they might well have been a Pareto improvement.

In this paper we consider in a consistent framework the financial redistributions implied by the three main public transfer systems: Education, Social Security and Medicare, providing useful information for assessing the impact of public transfers. For example, by looking at the timing and size of the various transfers, we can see whether Becker and Murphy's story may actually make sense, in light of the public transfers as they have occurred in the real world. Our work also allows to revisit the results of standard generational accounting, as developed by Auerbach, Gokhale and Kotlikoff (1991), and currently used by many governments as a measure budget balance.

Our work focuses on the financial redistribution and therefore is unable to draw definite conclusions about the welfare impact of intergenerational transfers. A welfare analysis would be much more complex since it would need to include three main elements: (i) a measure of the flows of transfers, (ii) an estimate of the indirect effects of transfers (due to externalities, distortions, offsetting behavioral responses, etc) and (iii) a widely accepted measure of individual welfare. We chose to deal only with the first point without making any assumptions about the last two, which are very controversial issues. Our conclusions are by construction of restricted scope, therefore, but robust.

Humans enjoy a long life span, but its length is a nightmare for researchers trying to measure transfers from a longitudinal perspective! People may live 110 years or more, receiving education in the very early years of their lives, and pensions on the very last day of their life. Thus to measure a single cohort's transfers, one needs data on transfers occurring over more than a century. Since our aim is to compare what happens to different cohorts, we need data covering far more than a century. In practice this means that the data must reach as far as possible into the past, and be extended through projections far into the future.

Our main effort has been to collect, construct and project data on Social Security, Medicare and Education, for generations born from 1850 to 2090. This involved intensive collection and construction of data for past transfers, as well as projections under particular assumptions about productivity growth, demographic change, and policy choices. The outcome for each system are matrices of the average value of benefits received and taxes paid by age, from 1850 through 2200, by single years of age and time. These matrices can be analyzed cross-sectionally for each calendar year, or across time for any given age, or diagonally by generation. Because we are interested in a longitudinal view, we focus mainly on the diagonals of the matrices, which we summarize by calculating for each generation the present value at birth of survivalweighted benefits received minus taxes paid over the life cycle. We have also calculated 
an age-earnings matrix for the same period, which we use to calculate the present value of survival weighted life time earnings. Results will often be expressed relative to these present values for each generation.

Our discussion makes it possible to identify the generations who received (or will receive) more transfers than they paid (or will pay) and those who paid more than they received. Moreover we are able to estimate the net loss and gains and to compare them with lifetime earning. As we will see, including public education substantially changes the pattern that people have in mind when they think about the flows of public intergenerational transfers. Some generations that are generally pointed out as having received a large "free lunch", because of the development of Social Security are also generations that paid for a much larger "lunch" than the one they consumed, because of developments in public education.

The structure of the paper is as follows. In section 2 we explain how we estimated and forecast public transfers. Section 3 provides the results for each transfer system, and their combination, and compares our results with those of generational accounts. Section 4 discusses the main insights derived from our work. Section 5 concludes.

\section{Estimation and forecasts of transfers Data and Methods}

The historical data for these three programs come from a variety of sources. Here we will briefly describe the data sources and methods used; some further details can be found in the appendix. For public education, age-specific benefit data were derived from census data on school enrollment rates and administrative data on total expenditures. Agespecific tax data were generated based on a balanced budget assumption together with the expenditure totals. We assumed that education was paid for by property taxes, and inferred the incidence of these taxes from census data on home ownership, renter status and income (Qian, 2003). For social security, published and unpublished age-specific administrative data came from the Social Security Administration. Age-specific tax data was derived from survey data on taxation and administrative data on sources of social security revenue.] For Medicare, age-specific benefit data were derived from administrative data on the age-distribution of benefits in 2000 and administrative data on total expenditures. Age-specific tax data were derived from survey data on taxation and administrative data on sources of Medicare revenue. For our historical series, we are more certain of the level of expenditures and taxation than the details of their age-specific allocation.

For the projection, our general technique is to assume a fixed cross-sectional age-shape for benefits and taxes, and to shift the levels of these age profiles upwards at a fixed rate which depends on the rate of productivity growth. However, there are many exceptions. Health care costs are projected to rise more rapidly than productivity growth, following the assumptions of the Medicare Trustees and Actuaries. Social Security benefits are determined for each cohort at retirement, and depend on the history of productivity growth, as well as on legislated changes in the normal retirement age. Education 
enrollment rates are assumed to continue at their level in 2000. Our simulation models have been carefully tested against official projections and other projections we have done, where these are available, and they accurately reproduce these.

Projections indicate that both Social Security and Medicare have major long term fiscal imbalances, and they are unsustainable as currently structured. While we do one set of projections based on current program structure, we also have specified three different adjustments to balance the programs: 1) raise taxes as necessary for period to period balance, once the trust funds are exhausted; 2) cut benefits to achieve balance; and 3) make equal adjustments to both taxes and benefits, which is our baseline assumption.

We assume a real (that is, inflation adjusted) interest rate of $3 \%$, and productivity growth of $1.6 \%$ (real covered wage growth of $1.4 \%$, allowing for changes in hours worked, fringe benefits, etc., following Social Security Administration assumptions). We assume that age-specific costs per Medicare enrollee grow $1 \%$ faster than productivity through 2080 and then trend down toward the rate of productivity growth. We forecast future mortality rates to be consistent with the Social Security Actuary's projections, which we then extend using Lee-Carter methods. The long-run total fertility rate is assumed to be 1.95, following recent Social Security assumptions. Annual immigration is set at 900,000 per year (Miller, 2004). ${ }^{1}$ For many of these assumptions we have performed sensitivity analyses (discount rates, educational enrollment growth, and budget balancing policies).

Based on these data sources, procedures, projections, and policy assumptions, we have constructed a complete age-time matrix of benefits and taxes for each birth cohort from 1850 through 2200, providing the data necessary for life cycle accounts for generations born 1850 to 2090 . This matrix is the basis of all the calculations reported below.

\section{Empirical Results}

Net Social Security and Medicare benefits by birth cohort: 1850 to 2090

As noted earlier, we calculate the net present value for each program and each birth cohort as the difference between the lifetime discounted, survival-weighted benefits and the discounted, survival-weighted tax payments. Figure 1 displays the present values for Social Security benefits received and taxes paid by different generations. Figure 2 does the same for Medicare. We will not discuss these in detail at this point, but instead turn to the Net Present Values, or NPVs.

Figure 3 presents these NPVs for Social Security and Medicare as a percent of the present value of lifetime earnings The creation of Social Security in the late 1930s (with first

\footnotetext{
${ }^{1}$ The budget is balanced each period using the full population age distribution, and assuming that immigrants are economically identical to natives at each age. This sets the level of taxes and benefits according to the specific budget balancing assumptions used. Then, based on these age schedules of taxes and benefits, we calculate the net present values (NPVs) for the native born population, since it would not make sense to calculate NPVs at birth for immigrants who arrive at later ages.
} 
regular benefit payments starting in 1950) and Medicare in the mid-1960s led to large windfall gains for the early participants in these pay-as-you-go systems. These early participants received benefits far in excess of the taxes they paid. The Social Security NPVs are highest, at about $+4 \%$ to $6 \%$, for the birth cohorts of 1890 to 1920 , with those born in 1914 experiencing the greatest windfall gain with the net present value of their combined social security and Medicare benefits amounting to $8.1 \%$ of their lifetime earnings. Rates of return might be higher for earlier cohorts, but the NPV depends also on the scale of benefits received, not just on their relation to prior contributions.

For cohorts born after 1920 , the NPV declines steadily to around $-2 \%$ to $-3 \%$ for cohorts born today, based largely on projections for the $21^{\text {st }}$ century. The NPV for Medicare reaches a peak of around 2\% for birth cohorts of 1910 to 1960 . The NPV declines for cohorts born after 1960 reaching about $-1 \%$ for cohorts born today.

Under our baseline scenario, the future shortfall in Social Security and Medicare is met in equal parts by raising tax rates and lowering benefit rates. In the case of Social Security, these adjustments begin 2044 when the trust fund is exhausted (according to SSA projections, it is exhausted in 2042). In the case of Medicare, adjustments begin almost immediately. Here we consider three alternative scenarios shown in Figure 4. In the first alternative, future shortfalls are met by cutting benefits. In this scenario, the NPVs are negative beginning with cohorts born in 1956. In the second alternative, future shortfalls are met by raising taxes. In this scenario, the NPVs remain positive until the generation born in 1981, but the NPVs for future generations are more negative than when benefits are adjusted rather than taxes. Finally, we consider the scenario in which there is no adjustment, and the systems are permitted to continue running deficits indefinitely. This is not a sustainable course since it leads to an explosion of debt. In this scenario, the NPV just keeps on rising as a share of life time earnings for generations born after 1960 or so, since taxes are not raised, nor benefits cut. Presumably the benefits are financed by the sale of bonds, for which in reality it is unlikely there would be any buyers since debt to GNP ratios would soar.

Net transfer benefits for Public Education by birth cohort: 1850 to 2090 An individual receives public education benefits at an earlier age than the taxes to fund education are paid. Therefore, such systems create implicit transfer wealth for the government rather than implicit transfer debt (the signs are reversed when we take the perspective of individuals). Whereas initial participants in the social security system received a windfall gain, the first generation to make tax payments to support the public education system receive a windfall loss as they pay for a level of educational benefits which they themselves have never received. 
The annual Trustees Reports of the Social Security Administration and Medicare contain projections of costs and revenues over a 75 year horizon, and methods for generating these are debated in the literature. However, for education, we have been unable to locate any comparable long term projections. Therefore we will discuss these in a bit more detail.

Our projections of costs are based on the numbers of school age children (derived from our general demographic projections), their enrollment rates by grade level, and the costs per enrolled student at each grade level. We project costs per enrolled student at each broad grade level, including higher education, to rise with labor productivity in general, on the assumption that schools must compete for workers in the general labor market. The background for our projections of enrollment rates is given in Figure 5, which plots the sum of enrollment proportions across ages for each calendar year, which we call the Total Enrollment Rate, or TER (analogous to the Total Fertility Rate, or TFR). This simple sum should correspond to the average years of schooling for each synthetic cohort, had it lived its life exposed to the enrollment rates of a single calendar year. It can be seen that the TER rises roughly linearly from 1850 to 2000 , with a slight deceleration in recent years. ${ }^{4}$

We have projected the TER in three ways. First, at the average of the historical trends for the US and France from 1960 to 2000 (which removes the effects of the recent slowdown in the US), at .95 years of increased schooling per decade until 2150, and flat thereafter. Second, at one half this rate, or .475 years of increased schooling per decade. And third, as our baseline assumption, at a continuation of the level in 2000 , that is with no further enrollment gains.

Figure 6 gives the present values for educational taxes and benefits separately, for the baseline scenario (enrollment growth ceases after 2004). Figure 7 presents the NPV for public education for each birth cohort from 1850 to 2090, for each of the three projection assumptions, calculated with a constant real interest rate of $3 \%$, and expressed relative to the present value of life time earnings.

To interpret Figure 7, first imagine what it would look like if public education were suddenly introduced all at once in one calendar year. In this case, the initial birth cohorts would pay taxes but receive no education themselves, so all would show a negative NPV. The cohort born five years before the start of public education would be ready to start kindergarten at the inception of public education, and would receive the complete education provided. Consider the NPV for this cohort. We know that the internal rate of return for any mature stable transfer system must equal the rate of population growth plus the rate of productivity growth, or the rate of growth of GDP. Since the educational benefit is received before the taxes are paid, we would expect the NPV to be negative if the discount rate is less than the growth rate of GDP, and positive if it exceeds the growth

\footnotetext{
${ }^{4}$ The TER is higher than the median educational attainment for several reasons. First, it includes kindergarten years. Second, it is a mean rather than a median. Third, it includes both part time and full time enrollment. Fourth, it includes time spent repeating grades.
} 
rate of GDP. A 3\% discount rate is below the growth rate of GDP for the early part of the period, and so should yield a negative NPV for the fully educated cohorts as well as the initial cohorts. The historical rates of interest should be a bit higher than the growth rate of GDP, and so yield a positive NPV.

In practice, however, public education was phased in very slowly. As enrollments and median grade attainments rose, each generation of tax payers funded a higher level of education than it received itself, so NPVs were negative. The generations that funded the education of the baby boom generation were hit particularly hard because there were so many students, and relatively few tax payers, and because of the timing of rapid enrollment increases. Those generations born between 1928 and 1942 all experienced losses of at least $5 \%$ of life time earnings through the educational system.

Figure 7 shows that the NPV becomes increasingly negative relative to life time earnings until it reaches its trough for the birth cohorts of 1937-38 at around $-6 \%$. After this it rises, but does not become positive until the birth cohort of 1958. It approaches a plateau in the $1980 \mathrm{~s}$, and ceases to rise in the 1990 s after reaching a level close to $+8 \%$. Since this outcome is based almost entirely on values of taxes and expenditures projected far into the $21^{\text {st }}$ century, we would expect the result to be sensitive to projection assumptions, but Figure 7 shows that it is not.

\section{Combined Accounts}

Figure 8 shows the NPV's for the combined upward transfer (through Social Security and Medicare) together with the NPV for the downward transfer through public education. The first generations to bear the cost of public education were too old to gain from the introduction of Social Security. However, to a considerable extent we see that those generations that benefited from the start-up of the upward transfers were the same ones that bore the brunt of the intensification of the downward transfers associated with financing the education of the baby boom. For example, for the cohort born in 1926, net social security and Medicare benefits amounted to $6 \%$ of lifetime earnings which were offset by net public education benefit amounting to $-4.5 \%$ of lifetime earnings, so that net effect of all transfer systems was just $+1.5 \%$ of lifetime earnings. Similarly, we forecast a future in which net public education benefits amount to $+7.8 \%$ of lifetime earnings for the birth cohort of 2004, while social security and Medicare account for a net loss of only $-2.6 \%$. So, the net benefits from all transfer systems for children born today are projected to be $+5.2 \%$ of lifetime earnings. All generations born between 1977 and 2002 will experience a greater NPV relative to earnings than the most fortunate generation at the turn of the century (the generation born in 1914 received 5.34\%). All generations born between 1948 and 2052, that is over the course of more than a century, are projected to attain positive NPVs when all three systems are considered together.

The current young and future generations are generally viewed as victims of our our profligate public policy, by which the current elderly live high on the hog at their expense. However, a typical elderly person of today was born seventy years ago, in 1934, and experienced a net loss of about one percent of life time earnings, while a baby born today is projected to realize a net gain of $5 \%$ ! This is the opposite of the story we are 
accustomed to hearing! Evidently, adding education to the mix dramatically changes the generational equity picture.

While largely mirroring each other, the difference in timing of the introduction and expansion of these transfer programs means that some cohorts received net fiscal benefits and others net fiscal losses. There are two peaks in net benefits. The first peak was centered on the cohort born in 1914 which experienced the large windfall gains from the start-up of social security but missed much of the windfall losses from the expansion of public education funding. On net, the 1914 cohort received net transfers amounting to $5.3 \%$ of lifetime earnings. The second peak in net benefit is centered on the cohorts born in 1992-93 which experienced the positive benefits of the educational expansion funded by previous generations and which are projected to avoid the looming net costs of paying the social security and Medicare implicit debt. On net, these cohorts are forecast to receive net benefits amounting to $5.8 \%$ of lifetime earnings.

There are three sets of cohorts which experienced net losses through the transfer systems. Those born before 1880 experienced net losses due to the expansion of the public education system. Those born between 1930 and 1947 also experienced net losses. While these cohorts did receive large windfall gains associated with the start-up periods for Social Security and Medicare, these were more than offset by windfall losses from the expansion of the public education system. Cohorts born after 2052 are expected to incur increasingly large net losses via the public transfer systems as Social Security and Medicare loom large relative to education. ${ }^{5}$

\section{Which generations benefit from cutting benefits versus raising taxes?}

It is also interesting to consider the consequences of different policies for adjusting the long term imbalance in our upward transfer systems. In our baseline projections, we assumed that the imbalance was addressed half by reducing benefits and half by raising taxes, once the trust funds were exhausted. Here, we will also consider the policies of leaving benefits as currently legislated while raising taxes to eliminate imbalances, and the opposite policy of cutting benefits as necessary to conform to tax revenues generated

5 Note that our calculations implicitly assume that direct expenditures on public education earn a rate of return equal to the rate of discount we use in the calculation, here $3 \%$. In a sense, then, they assume that the level of investment in education is optimal, so that its rate of return equals that on other assets. But if there are higher returns to education, and most likely there are, then later generations could have negative combined NPVs, and still realize life time gains from the transfer program. We have not attempted to include such possibly higher rates of return in our calculations. In fact, most estimates of the rate of return to education are based not on direct expenditures but rather on the opportunity cost of the students' time, and so might not be an appropriate basis for the calculation. Furthermore, there might well be externalities to education that transcend the individual's returns, such as are incorporated in a number of models of endogenous economic growth. So for now, at least, this straightforward calculation seems to be the best way to go. 
by current tax policies for these transfer systems. In all three cases, the policy for education is left unchanged.

The results are shown in Figure 9, which plots the NPVs under each policy scenario. We see that the policy of raising taxes to maintain benefit levels has intergenerational effects that are qualitatively similar to the baseline policy, although the quantitative differences are large: young generations of today have much higher NPVs if benefits are maintained, while generations after 2050 suffer much greater losses, relative to the "share the pain" baseline policy. The third policy, of cutting upward transfer benefits to stay within tax revenue constraints, has a strikingly different outcome: generations born after 1975 all have a constant positive NPV of about $2 \%$, apparently in perpetuity. Without going into the detailed implications for the upward transfer benefits, however, it is clear that this policy regime entails drastic cuts in both pensions and health care for current and future generations.

Now let us consider the implications for all generations alive today, by calculating their NPVs looking forward from their age in 2004, rather than from birth. Doing this indicates the effects of the different policy options on their remaining interactions with the public sector transfer programs, and thereby shows their narrow self-interest in different policy options. ${ }^{6}$ Figure 10 plots the results. First consider the baseline curve. We see that the NPVs are positive at all ages, except for ages 12 to 37, with a low in the early 20s with a loss of around 60 thousand dollars. The NPVs peak at 65, with a value of $\$ 260,000$.

Clearly and unsurprisingly, the elderly have the greatest stake in maintaining the system.

Now consider the contrast between raising taxes (the upper line) and cutting benefits (the lower line). We see that every single generation alive today, even those just born, would gain from raising taxes! Those who would gain the most are the generations between age 20 and 60 in 2004, for whom the difference amounts to around $\$ 80,000$. Furthermore, by returning to Figure 9 we can see that generations not yet born, all the way through 2040, would also gain from the policy of raising taxes. Needless to say, however, these gains come at a great loss to later generations, with those born in 2090 losing $12 \%$ of their life time earnings relative to the benefit-cut option, and with the proportionate losses continuing to grow rapidly thereafter. According to this analysis, it appears that the gains from restricting benefits for the elderly are not realized by any generation alive today, nor to be born in the next half century, but only thereafter.

\section{Sensitivity to rates of discount}

Because the NPVs are based on discounting over life cycles that last up to 110 years, one might expect that our results would be very sensitive to the discount rate used. Figure 11 displays the results of a sensitivity analysis, in which calculations are carried out for our baseline of $3 \%$ per year real, but also for $5 \%, 2.2 \%$, and the raw and smoothed historical rates of interest on short term Treasury Bills. In general, higher rates of interest reduce the importance of benefits received late in life relative to those received early, and lower

\footnotetext{
${ }^{6}$ These NPVs are also useful for comparisons to Generational Accounting, which presents numbers of this sort for living generations, rather than the NPVs at birth which we have so far considered.
} 
rates have the opposite effect. Thus the 5\% rate makes the windfall gains of the generations born close to 1900 relatively smaller and the gains from education of those born around 2000 relatively bigger, while both versions of the historical rate of interest have the opposite effect. However, the qualitative results appear to be surprisingly robust.

Are these results consistent with other generational accounts?

How can these results be consistent with the findings of generational accounting (Auerbach, Kotlikoff and Gokhale, 1991), which finds that future generations will be burdened more heavily than current ones? First, Auerbach et al examine the entire federal budget, and include explicit government debt in their calculations. Our analysis is limited to the major transfer programs and do not include debt. Second, Auerbach et al calculate the average net tax burden born by all future generations over an infinite horizon, whereas we look specifically at how the net tax burden might be allocated across generations born through 2090 under different policy regimes, and do not consider the infinite horizon. When our figures are compared to theirs, taking these differences into account, the results appear to be consistent (Figure 10 is useful for such comparisons).

We can also compare our calculations of current implicit debt to related calculations by Gokhale and Smetters (2003), who report the net present value of expected future taxes and benefits for the population age 15 and over in 2002, under current program rules with no future budget balancing adjustments. (This value plus trust funds equals their measure of Generational Imbalance, GI). They calculate a NPV of \$15.4 trillion for Medicare and \$10.1 trillion for Social Security. Under our "current law" assumptions, and restricting our calculation to the population 15 and over in 2002, we find $\$ 17.9$ trillion for Medicare and $\$ 16.5$ trillion for OASI. Our assumptions differ in several respects, most notably they assume a discount rate of $3.6 \%$, a growth rate of GDP per capita of $1.7 \%$, and do not include Medicare receipts from general revenue in calculating the NPV for Medicare. We assume a discount rate of $3 \%$ and a productivity growth rate of $1.6 \%$ (with covered earnings growing at $1.4 \%$ ). In calculating the NPV for Medicare, we include future income from general revenues.

\section{Discussion}

Human capital is one of the main generators of economic growth. As shown by past experience, as well as the on going situation in developing countries, public funding of education is the best way to insure that human capital grows quickly. But "public funding" for education translates into "downward transfers" viewed either crosssectionally or longitudinally.

Historical data on transfers show that these downward transfers have actually been very costly for some generations. For example transfers for public education have cost more than 5\% of their lifetime earnings to the cohorts born between 1928 and 1942. Was it legitimate to ask these generations to give up more than $5 \%$ of their life time earnings for future generations who, hopefully, will also have a better life? Or should we see the development of public upward transfers, that did give a free lunch to these same 
generations, as a legitimate counterpart to the financial efforts they were asked to make for the development of public education? Without making a statement about what is or is not legitimate, our results simply show that the cohorts born between 1928 and 1942 have been more or less repaid, through Social Security and Medicare, for the costs they incurred for the development of public education.

Nonetheless, there are some generations that have paid (or will pay) more than they received and vice versa. The three kind of intergenerational transfers we consider do not cancel out and are actually the source of some financial redistribution between generations.

The first point to notice is that generations born between 1850 and 1880 did pay more than they received. These generations were at the beginning of the development of public intergenerational transfers and were perhaps not compensated by externalities arising from a more educated society. For them the development of the welfare state may well have been costly. The cost remained moderate, however, peaking at $1.4 \%$ of life time earnings.

Generational accounts turn to positive for cohorts born between 1880 and 1937 and then remain above minus $1 \%$ for all cohorts we consider in this analysis until 2060 . But it is clear that the growth in human capital that was facilitated by the development of public education from the middle of the nineteen century, had an effect through economic growth that largely compensated or reversed this minor loss. In other words, even if some generations born after 1930 paid slightly more than they received for public transfers, they all benefited from public transfers. Thus, apart from the generations born before 1880 , our data are consistent with the Becker and Murphy argument.

Nonetheless, Figure 8 does raise some questions. First, were upward transfers developed only to compensate for downward public transfers for education? Our results do not support such a view, since generations born between 1880 and 1930 actually received significantly more from Social Security and Medicare than they paid for public education. Actually, intergenerational transfers considered as a whole did redistribute resources from generations born after 1930 to those born earlier. The higher life time incomes of those born after 1930 might justify doing so, but this redistribution should not be ignored.

The question that naturally follows is why the negative NPVs for generations born between 1930 and 1947 were followed by increasingly positive ones for subsequent generations through 2052, who are richer, or are expected to be so. The rationale for this redistributive aspect of public intergenerational transfers is therefores not obvious. It may be the case that externalities, and in particular economic growth, were greater for those born in the 1930s and '40s, and that the overall gains have a different shape than the NPVs, but it is difficult to make any such statement without having a very good understanding about what actually drove economic growth. 
Finally, we cannot ignore the fact that for generations born after 2052, the NPVs turn increasingly negative, with no end in sight to the trend which has dropped the NPV below $-4 \%$ by the end of our projection. These negative NPVs might easily be overwhelmed by positive externalities to education, but we have no evidence on this point.

It is well known that the long term budgets of both Social Security and Medicare are seriously out of balance, a problem that must be addressed in one way or another. Our analysis suggests that all current generations would gain from policies that preserve benefit levels by raising taxes, as against the reverse, and that is also true for their children and grandchildren. The big gainers from benefit cuts are generations far in the future, but in the absence of such reform their losses may be enormous. 


\section{Appendix: Methods and Data Sources for Estimates of Generational Accounts}

For purposes of this paper, we need calculations of the net present value of benefits received by a member of a generation over the life cycle, minus taxes paid over the life cycle to provide this benefit. The necessary ingredients for the calculation of the net present value (NPV) are an interest rate, $r$ (or a series of interest rates, $r(t)$, for the life time of the cohort: survival rates); survival probabilities $1(\mathrm{x}, \mathrm{t}) / 1(0)$ for each birth cohort; and the cost of the average benefits received by age, $\beta(x, t)$, and taxes paid for this benefit, $\tau(\mathrm{x}, \mathrm{t})$, also over the full life cycle. Given these, the NPV for the generation born in year $\mathrm{s}$, with constant discount rate $r$, is given by:

$$
N P V(r)=\int_{0}^{\omega} e^{-r x}(l(x, s+x) / l(0))(\beta(x, s+x)-\tau(x, s+x)) d x
$$

The NPV for Social Security, starting with the first generations to receive any benefits, has been calculated by others (Leimer, 1994; Schieber and Shoven, 1999). Calculations close to this NPV for Medicare, but differing in some important respects, have also been made (Cutler and Sheiner, 2000). Calculations for education have not previously been made. They are not at all straightforward, and have required extensive analysis of historical data, as described below. In this paper, we will present consistent calculations for all three, and for their sum, for the relevant generations, including some projections for the future.

\section{Methods for estimating NPV for public education, Social Security, and Medicare}

For public education, we estimated benefits, $\beta(x, t)$, and taxes paid for this benefit, $\tau(x, t)$, for birth cohorts from 1850 to 2000 . The population, education expenditure and taxes data mainly come from the US Census (Integrated Public Use Microdata Series, or IPUMS). Data are available at the micro level for each census year between 1850 and 1990, except 1890 and 1930. Between available census years, we use interpolation and smoothing to obtain estimates for single calendar years.

\section{Calculating the cost of educational services received by age}

In the census data we get from IPUMS, educational expenditures are not given. To calculate the public expenditure per capita for each year, we use public expenditures per pupil, which is either directly available or is derived from total expenditures and total enrolled students (taken from the Historical Statistics of the United States and Digest of Education Statistics). The total enrollment in public schools was calculated by multiplying the enrollment rates from IPUMS by the proportion of total enrollment that was in public schools (that is, we adjusted for private school enrollment). When day care and nursery school enrollments were reported, we eliminated all enrollments under age 5. Expenditure data did not distinguish between elementary and high school. For future years, we assume that the expenditure per pupil for public education will grow at the same rate as the projected labor productivity growth rate, which we assume to be $1.8 \%$ per year (in real terms). Incomes by age are likewise assumed to grow at this rate. 


\section{Calculating the taxes paid for education, by age}

Public education has always been funded mainly by property taxes. We assume that property taxes are proportional to property value. In the census, this value is reported by respondents who own their own homes. Renters report their average monthly rent which we assume is proportional to the value of the property. We use census data from 1940 to 1990 to derive the age profile of home value for heads who own their homes and the age profile of monthly rent for heads who pay rent. Data from the BEA (Bureau of Economic Analysis) give the aggregate value of residential housing by tenure: owned and rented from 1925 to 1990 . We use these data to adjust the levels of the two age profiles. We assume that $70 \%$ of property taxes on rental properties are passed on to renters in higher rents. The age profile of the value of landlord-owned homes is the same shape as the age profile of owned-home values.

We assume a balanced education budget for each year, so that total taxes paid for education exactly equal total public expenditure on education. The level of the age profile of tax payments is adjusted so that given the population age distribution, the appropriate total of tax payments is generated. Finally, using the survival rates for each cohort, and an interest rate or set of interest rates, we calculate the NPV according to the equation given earlier. We carry out the calculation both for a constant real interest rate of $3 \%$ (our preferred estimate) and for the actual historical real interest rate for each year.

\section{Calculating the costs and benefits for Social Security and Medicare}

For Social Security and Medicare, we can rely on administrative data for the historical period. For the projection period, we rely on simple age-based projection models. These simple models quite closely match the official financial projections issued by the Social Security and Medicare Trustees. We must use our own models rather than rely on official projections for two reasons. First, age profiles of average benefits and taxes are not included in the official projections. Second, we want to be able to perform sensitivity analyses by altering the assumptions about the demographic and economic future. 


\section{References}

Auerbach, Alan J., Jagadeesh Gokhale, and Laurence J. Kotlikoff (1991) "Generational Accounts: A Meaningful Alternative to Deficit Accounting," in David Bradford, ed., Tax Policy and the Economy (MIT Press, Cambridge, for the National Bureau of Economic Research), pp.55-110.

Becker, Gary S and Kevin Murphy (1988) "The Family and the State", Journal of Law and Economics, XXI, 1-18.

Boldrin, Michele and Ana Montes Alonso (1998) "Intergenerational transfers institutions: public education and public pensions" Paper presented at the CEPR/IIEG PBM Workshop on "Rethinking the Welfare Society", La Coruna 27-28 September 1998.

Cutler, David and Louise Sheiner (2000) "Generational Aspects of Medicare", American Economic Review, 90(2), May 2000, 303-307.

Gokhale, Jagadeesh, and Kent Smetters (2003), Fiscal and Generational Imbalances: New Budget Measures for New Budget Priorities , (Wash ington, D.C.: American Enterprise Institute).

Kaganovich, Michael and Itzhak Zilcha (1999) "Education, social security, and growth" Journal of Public Economics 71, 289-309

Leimer, Dean R. (1994), Cohort-specific Measure of Lifetime Net Social Security Transfers, ORS Working Paper No. 59, Office of Research and Statistics, Social Security Administration.

Masson, André (1999), Économie des solidarités -II-Familles, État et contrat générationnels, Document de travail du DELTA 1999-18.

Miller, Tim. (2004), A simple projection model of OASI finances, Manuscript, Department of Demography, UC Berkeley.

Qian, Wenlan (2002), Education Project Report, Manuscript, Department of Demography, UC Berkeley.

Rangel (2000), Forward and Backward Intergenerational Goods: A theory of intergenerational exchange, NBER Working Paper No. W7518.

Schieber, Sylvester J. and John B. Shoven (1999), The Real Deal: The History and Future of Social Security, (New Haven: Yale University Press).

Zhang, Jie (1995) "Social security and endogenous growth" Journal of Public Economics 58, 185-213. 
Fig 1. Present Value at Birth of Social Security Benefits (solid) and Taxes (dashed)

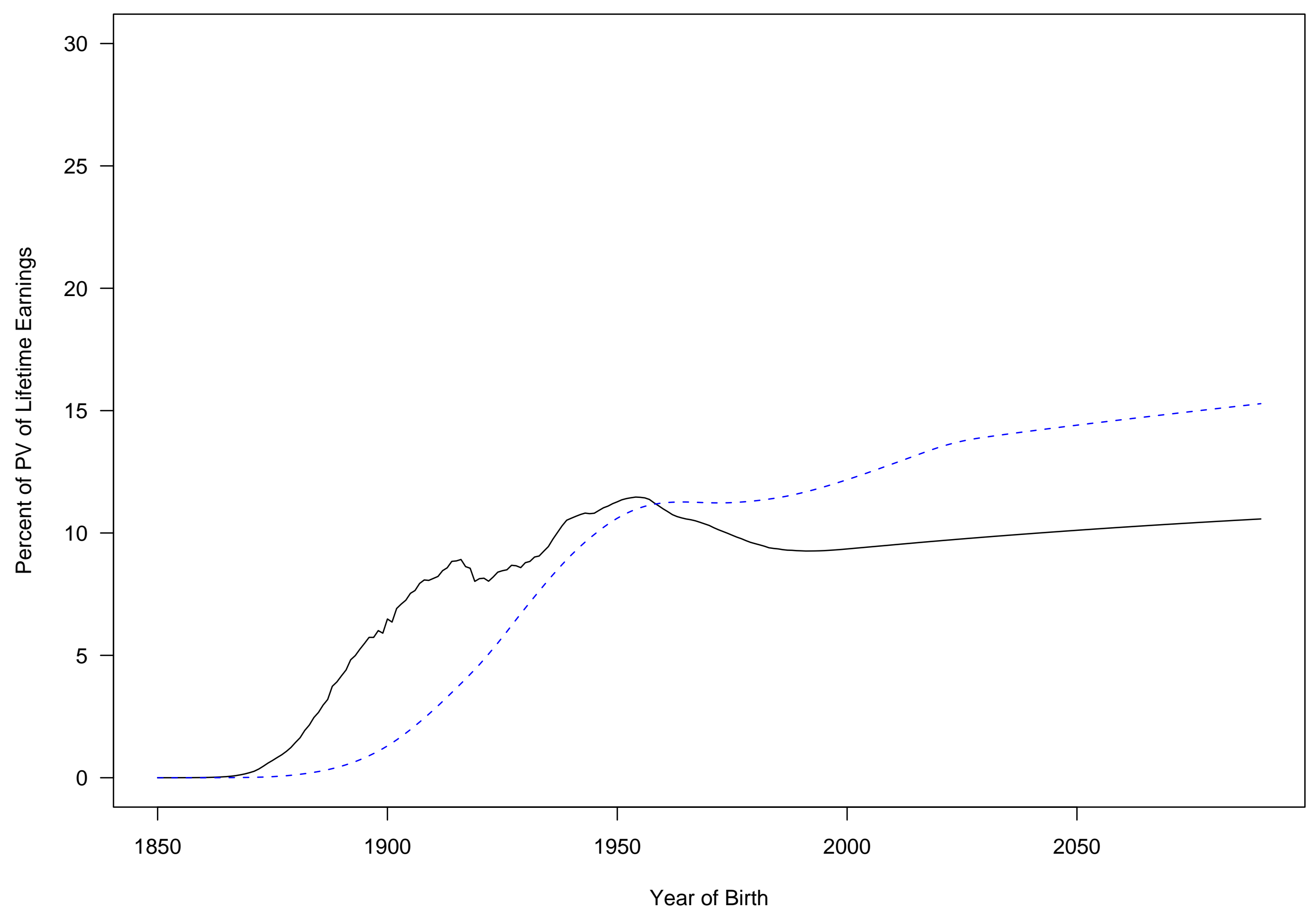


Fig 2. Present Value of Medicare Benefits (solid) and Taxes (dashed)

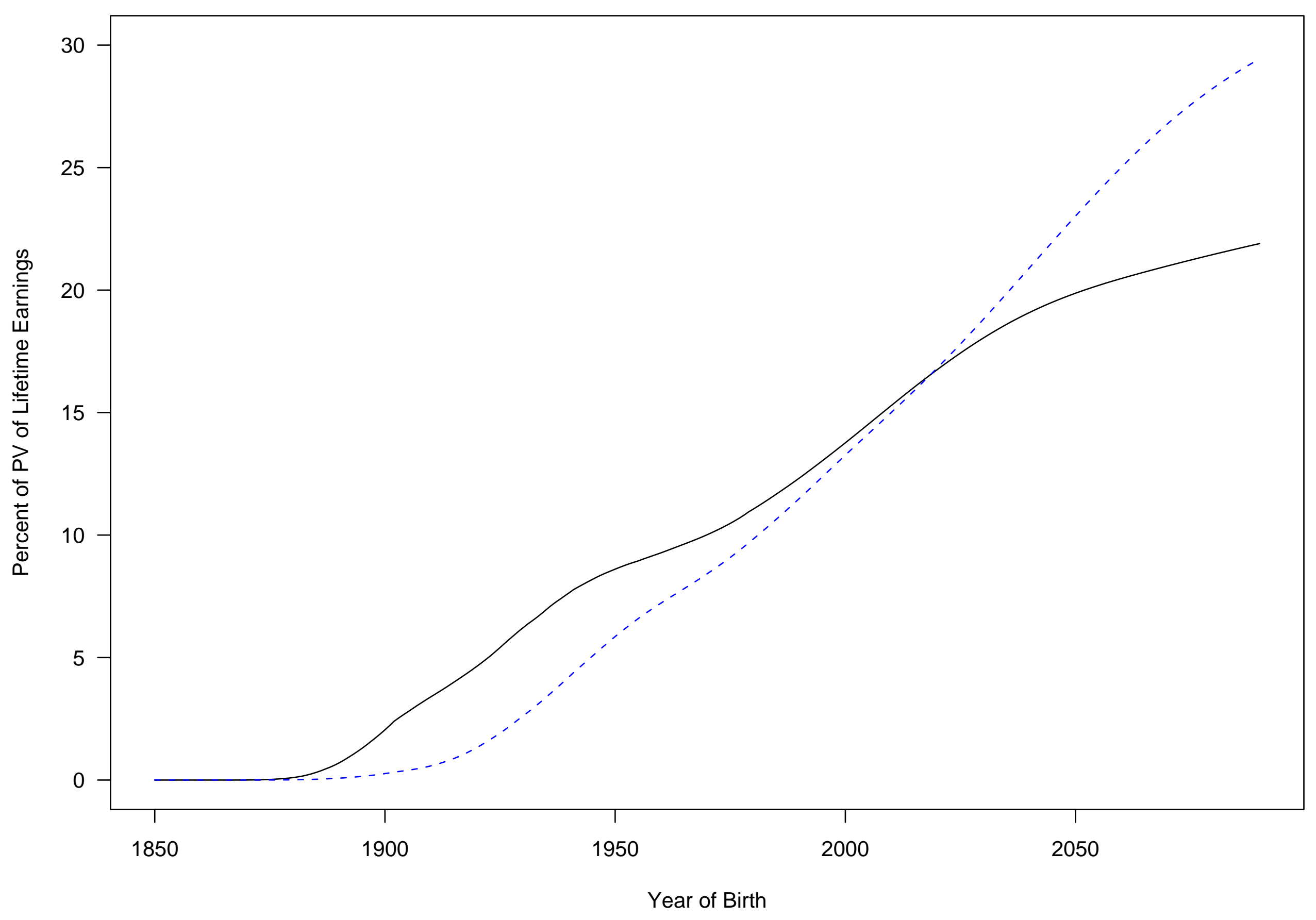


Fig 3. NPV at birth of expected lifetime Social Security and Medicare benefits as percent of lifetime earnings

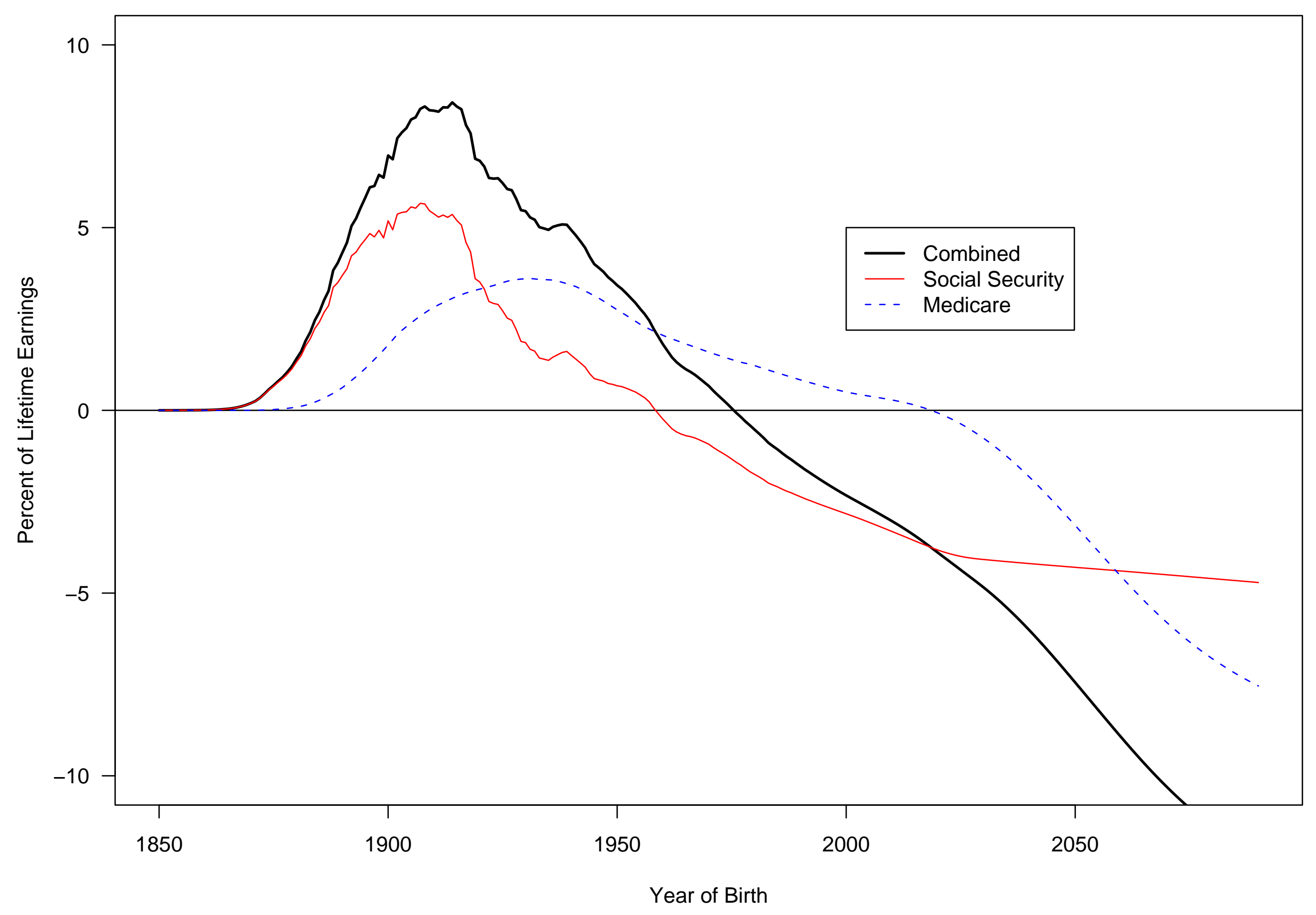


Fig 4. NPV at birth of expected lifetime Social Security and Medicare benefits as percent of lifetime earnings

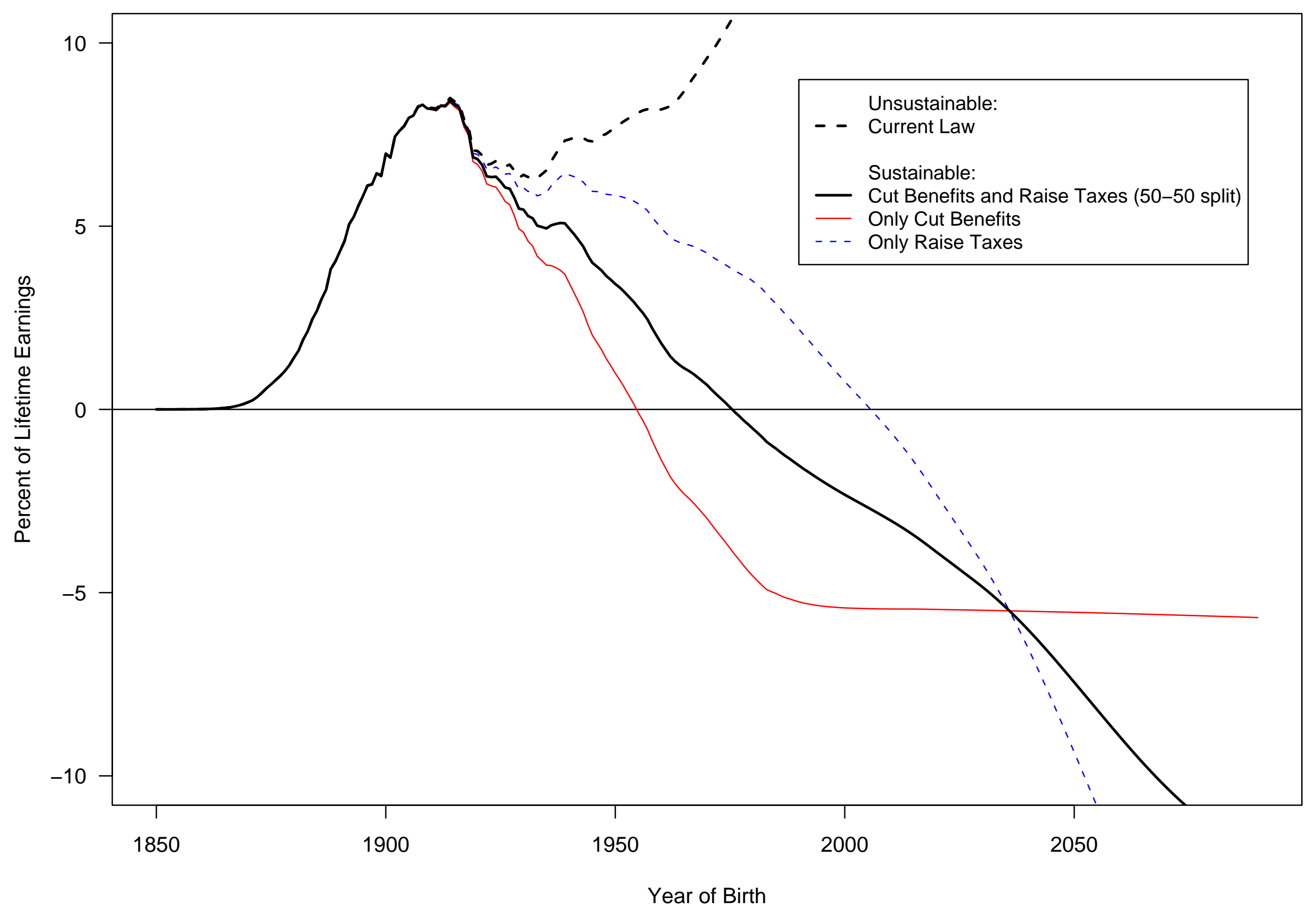


Fig 5. Person-years of schooling: Historical and Forecast

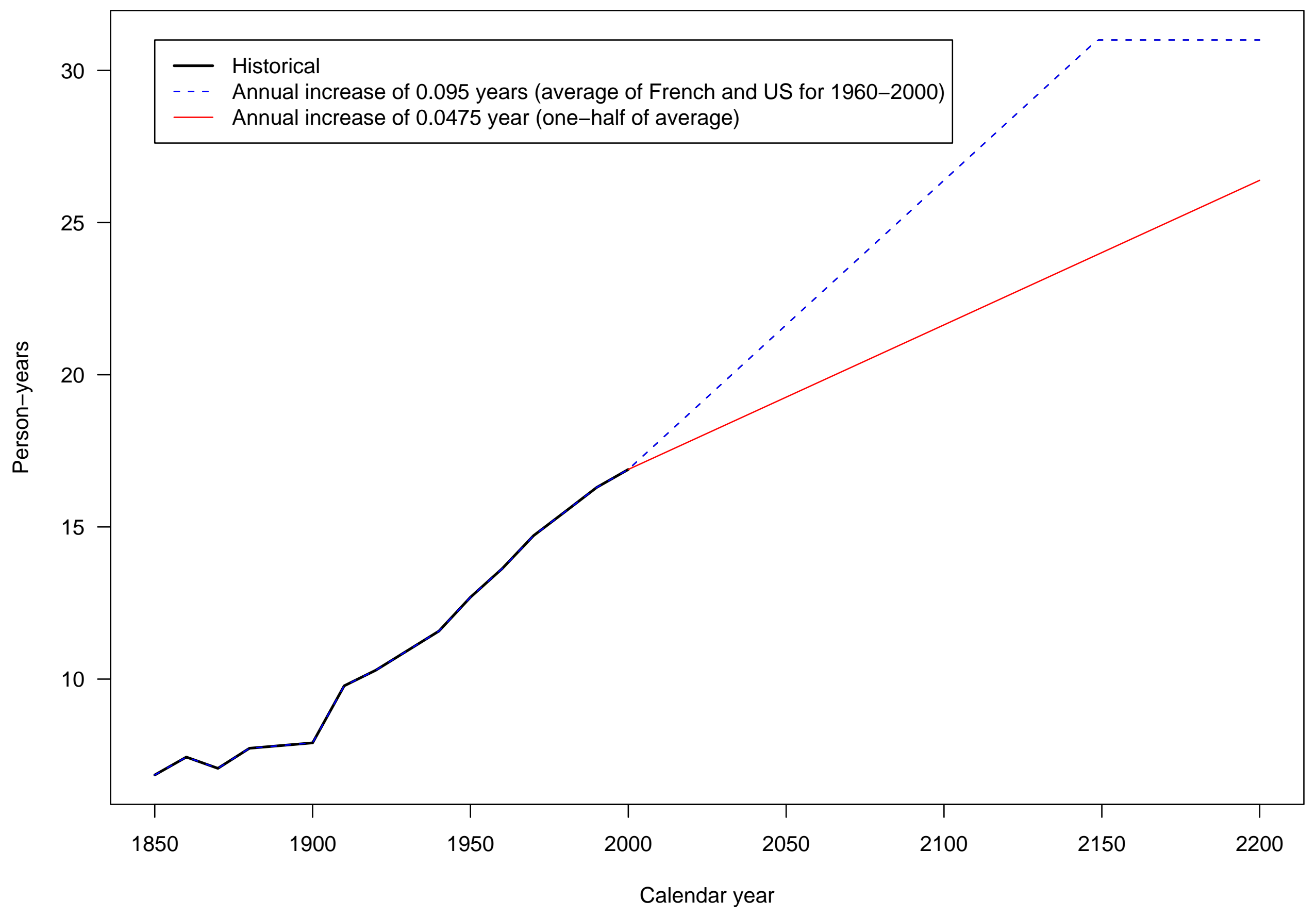


Fig 6. Present Value of Education Benefits (solid) and Taxes (dashed)

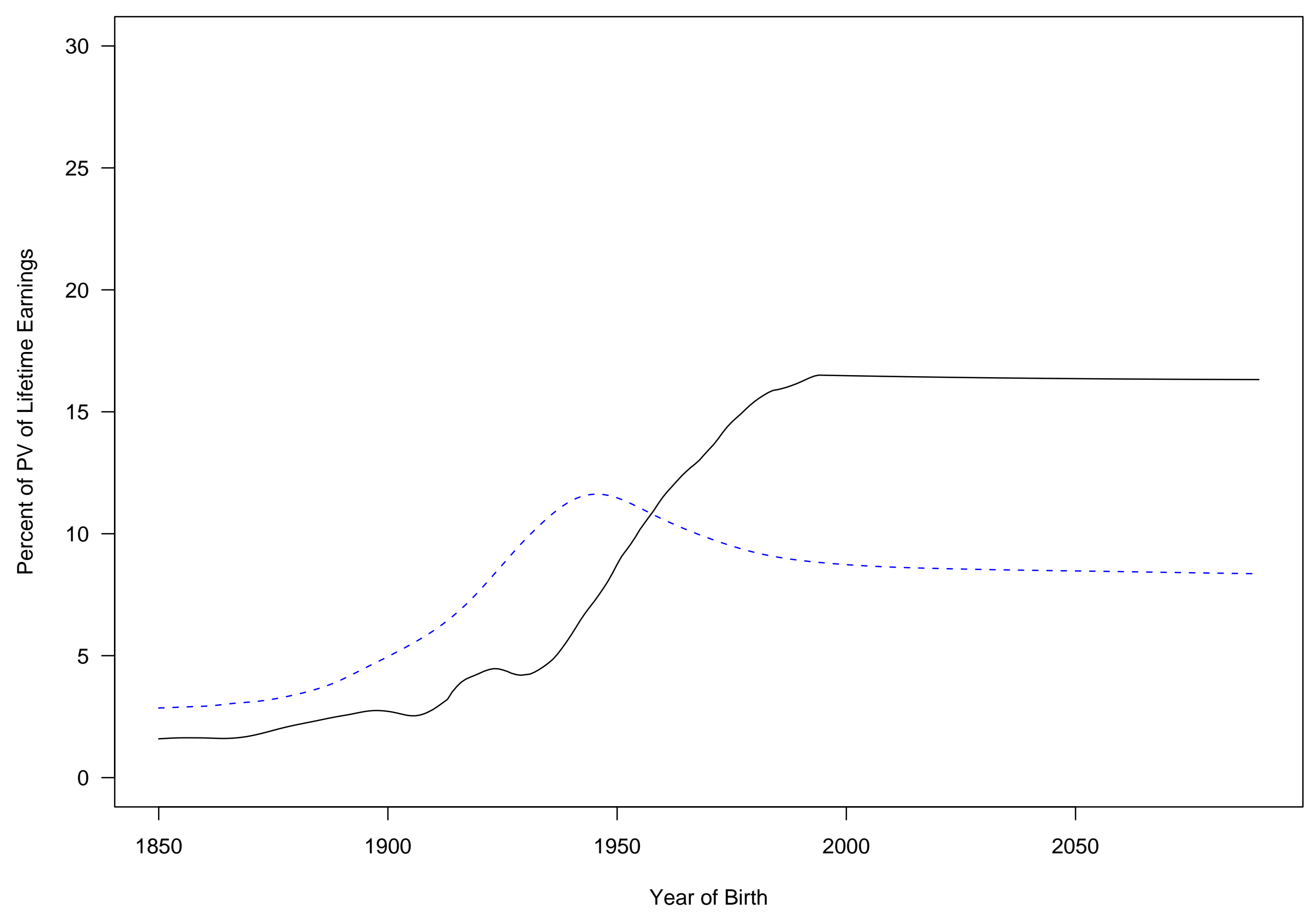


Fig 7. NPV at birth of expected lifetime Education benefits as percent of lifetime earnings

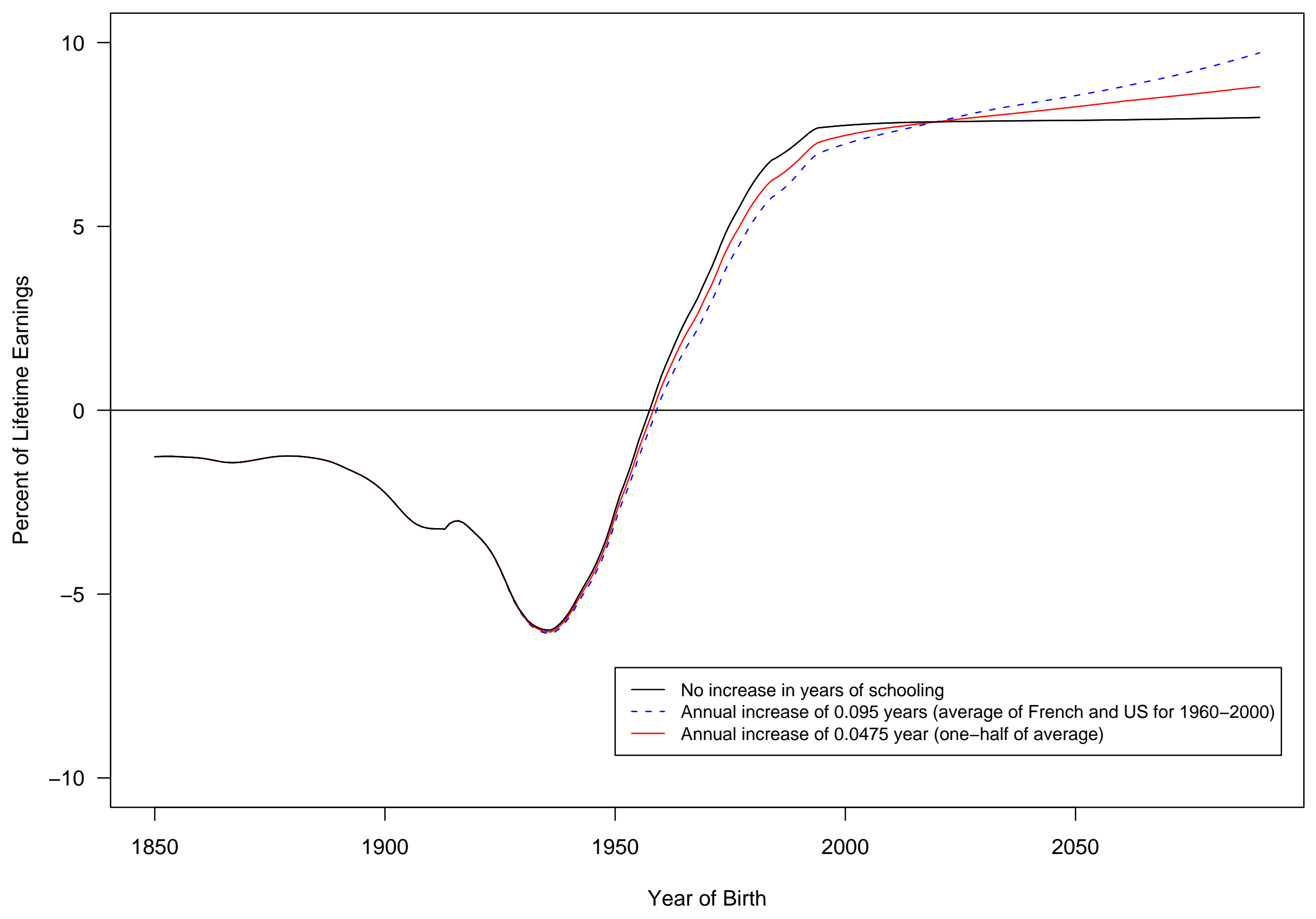


Fig 8. NPV at birth of expected lifetime Education, Social Security and Medicare benefits as percent of lifetime earnings

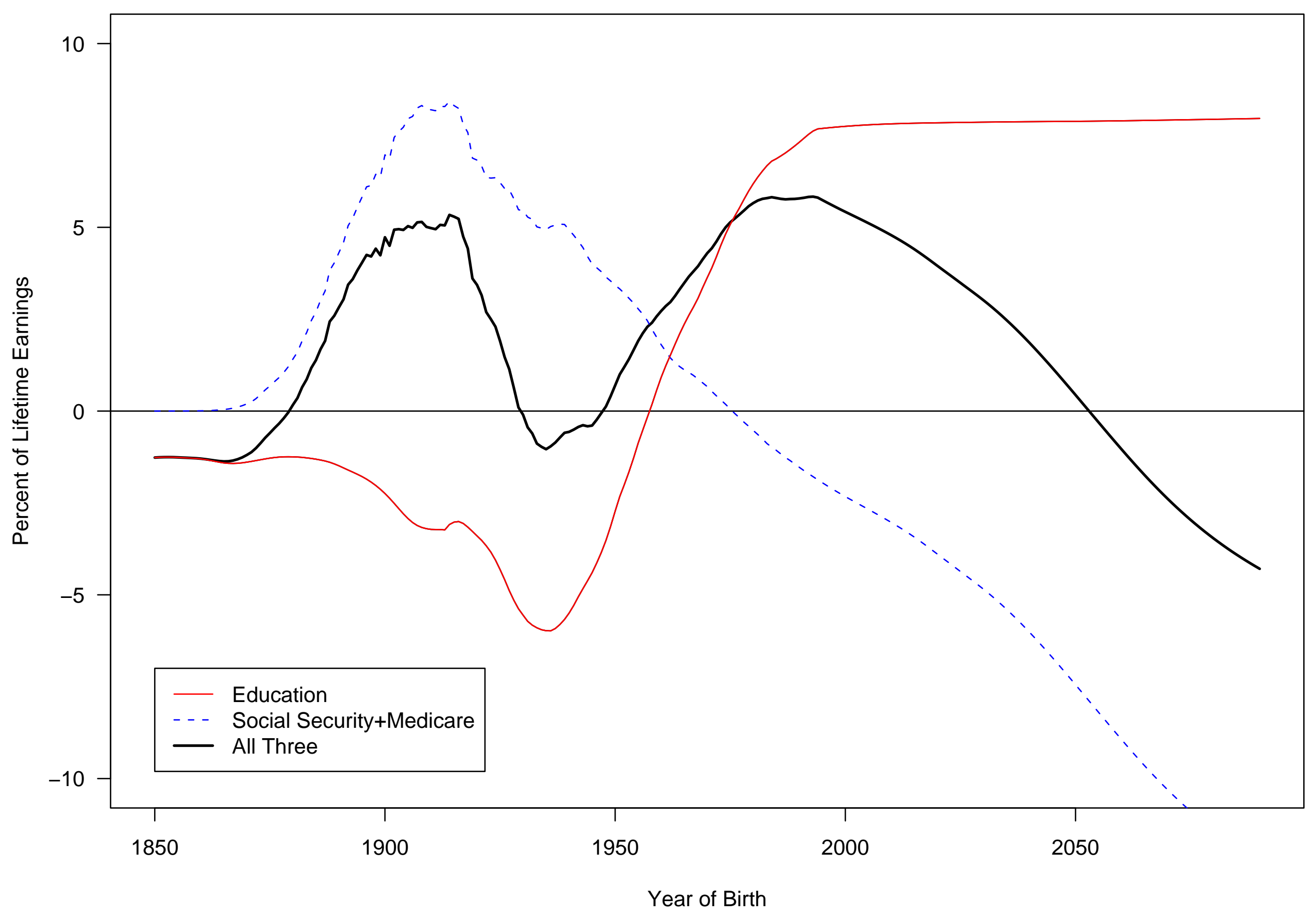


Fig 9. Budget Balancing Policy Options: NPV at birth of expected lifetime Education, Social Security and Medicare benefits as percent of lifetime earnings

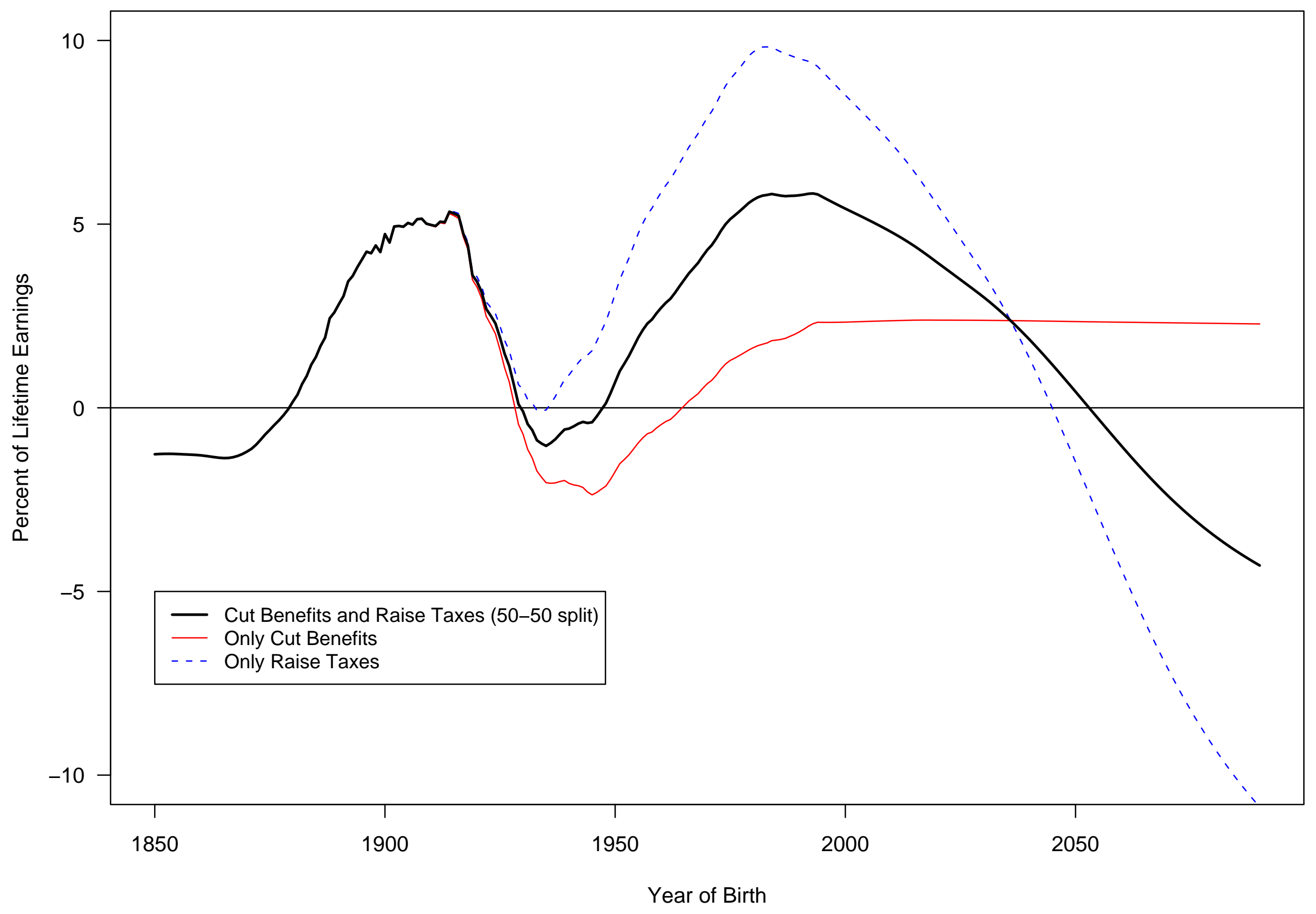


Fig 10. Net present value of participating in all transfer systems by age in 2004

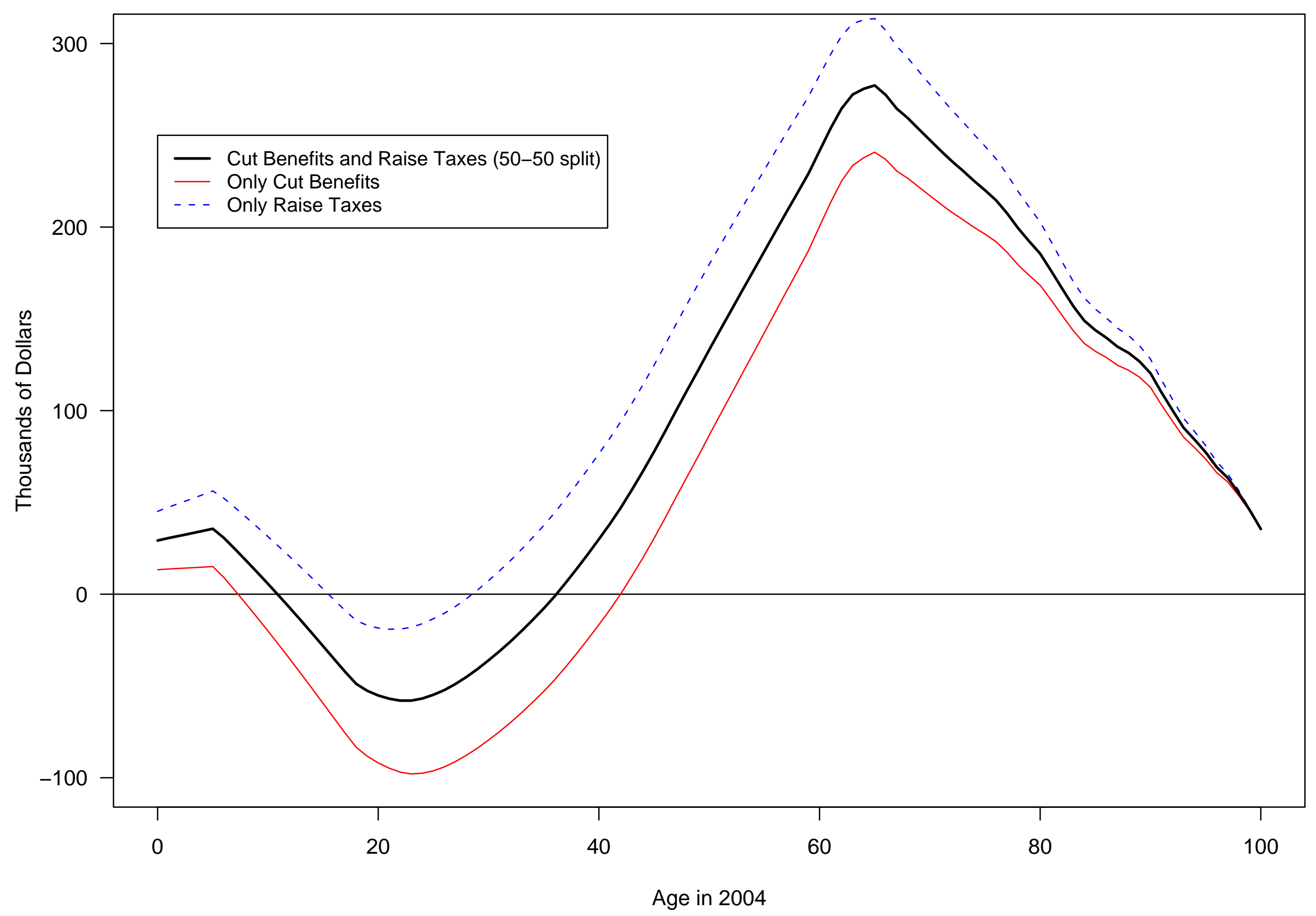


Fig 11. Sensitivity Tests of NPV Using Various Discount Rates

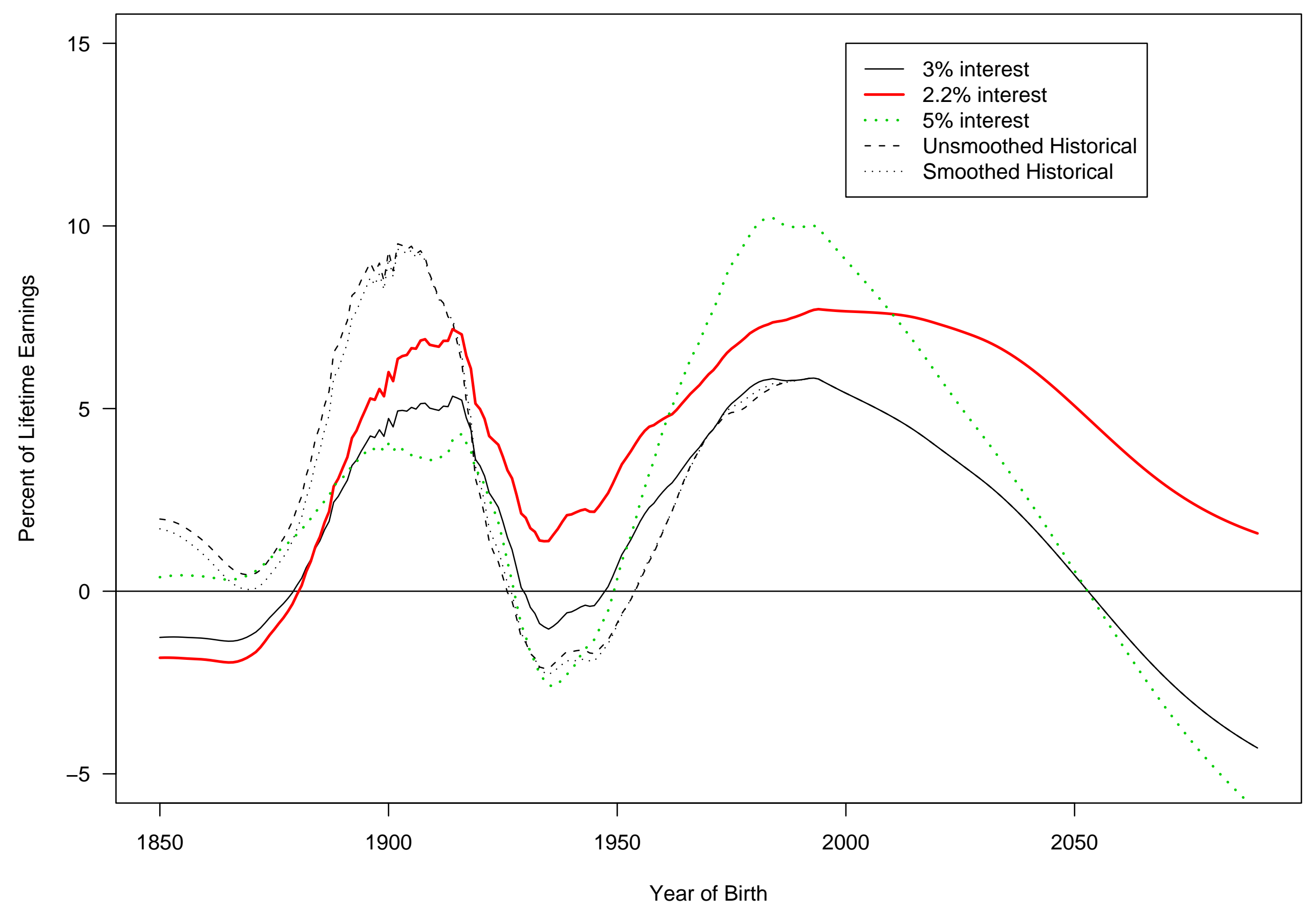

